\title{
Biotransformation of Ilicic Alcohol with Aspergillus Niger
}

\author{
Leticia Pous, Roberto Carrizo, Marcela Kurina Sanz, José C. Gianello and Eduardo Guerreiro \\ Química Orgánica- INTEQUI-CONICET- Facultad de Química, Bioquímica y Farmacia UNSL, Cha- \\ cabuco y Pedernera (5700)- San Luis, República Argentina \\ E-mail: alpous@unsl.edu.ar
}

\begin{abstract}
: $3 \beta$-hidroxyilicic alcohol was obtained from of ilicic alcohol using cultures of Aspergillus niger.
\end{abstract}

\section{Introduction}

Sesquiterpenes are wide spread Asteracea Compositae family. Their derivatives present several biological activities. Among them we have studied their gastrointestinal citoprotective action and the antinflamatory effects. The production of active metabolites by transformation of low funcionalized natural products is an attractive idea. In previous reports we have described the hydroxylation of the eudesmane, ilicic acid, in positions $1 \beta$ y $2 \beta$ [1] and the production of trihydroxyderivatives in positions $2 \beta$ y $3 \alpha$ from kudtdiol [2] by Cunningamella echinulata.

\section{Materials and methods}

Culture Conditions: Modified Czapek broth [3] was used to carry out the biotransformation reactions. Agar Czapek was employed to maintain the strains. Taking into account a previous screening, we have chosen an Aspergillus niger strain, isolated from aerial parts of Artemisia donglassiana. Biotransformations were performed according to a two steps fermentation process.

Biotransformation products were recover from the culture media by liquid-liquid extraction with $\mathrm{Et}_{2} \mathrm{O}$ and purified by $\mathrm{CC}$ with a gradient of $\mathrm{n}$-hexane/AcEt. $80 \mathrm{mg}$ of the biotransformation product were obtained. The hydroxylation position was defined by NMR and MS analysis.

\section{Results and Discusion}

The comparison of the ${ }^{1} \mathrm{H}$ NMR spectrums in $\mathrm{CCl}_{3} \mathrm{D}$ of the new product versus the ones of the substrate suggested us that the hydroxylation position was $3 \beta$. The sing at $\delta 3.43 \mathrm{ppm}$ was attributable to a geminal hydrogen in $\alpha$-equatorial conformation. This proposal was confirmed through the coupling pattern $(\mathrm{J}=11.5 \mathrm{y} 4.5 \mathrm{~Hz}) .{ }^{1} \mathrm{H}-\mathrm{NMR}$ shifts are in accordance with the ones recently reported for $3 \beta$ hydroxylicic acid isolated from other sources [4]. The impossibility to obtain the acetonic derivative 
confirm that the hydroxylic group was introduced in position in C-3, trans respect to the hydroxylixc group in C-4.

It was recently reported that Cunninghamella echinulata NRRL 3655 hydroxylated both, ilicic acid and kudtdiol in positions $\mathrm{C}-1 \beta, \mathrm{C}-2 \beta$ y $\mathrm{C}-3 \alpha$. These results, together with the ones reported here, shown us the ability of these microorganisms to hydroxylate in positions cis respect to the methyl grops in $\mathrm{C}-4 \mathrm{y} \mathrm{C}-10$

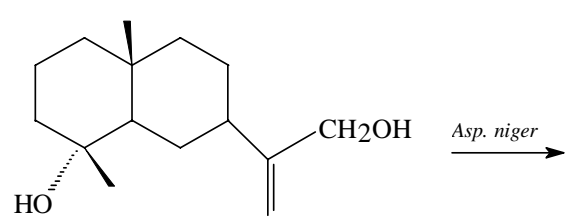

1

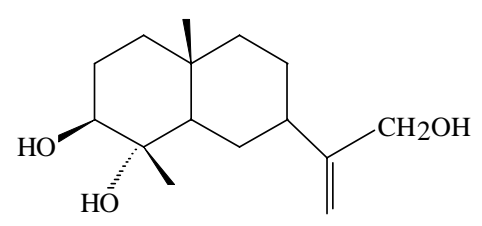

2

Acknowledgements: This work was realises within the Project 7301 supported by U.N.S.L. and CONICET, under the supervision of Dr. Eduardo Guerreiro. Authors thanks to Mr. José Villegas for the technical assistance.

\section{References and Notes}

1. Pous, L.; Carrizo, R.; Donadel, O. J.; Kurina Sanz, M.; Guerreiro, E. Nat. Prod. Lett. 1998, 12 (3), 231-235.

2. Carrizo, R.; Tonn, C. E.; Guerreiro, E. Nat. Prod. Lett. 1998, 12 (4), 271-276.

3. Pruna, B. R.; Bhattacharya, P.R. Applied Microbiology 1969, 10, 524.

4. Abu Zarga, M.; Hamed, E.; Sabri, S.; Voelter, W; Zeller, K. J. Nat. Prod. 1998, 53, 803-809. 